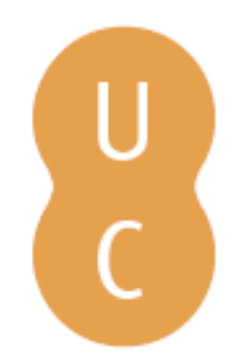

\title{
pompalina
}

\section{Sobre a preservação do património cultural edificado em Moçambique}
Autor(es):
Carrilho, Júlio; Lage, Luís
Publicado por: Imprensa da Universidade de Coimbra
URL persistente:
URI:http://hdl.handle.net/10316.2/44308
DOI:
DOI:https://doi.org/10.14195/978-989-26-1556-1_3
Accessed : $\quad$ 26-Apr-2023 12:35:15

A navegação consulta e descarregamento dos títulos inseridos nas Bibliotecas Digitais UC Digitalis, UC Pombalina e UC Impactum, pressupõem a aceitação plena e sem reservas dos Termos e Condições de Uso destas Bibliotecas Digitais, disponíveis em https://digitalis.uc.pt/pt-pt/termos.

Conforme exposto nos referidos Termos e Condições de Uso, o descarregamento de títulos de acesso restrito requer uma licença válida de autorização devendo o utilizador aceder ao(s) documento(s) a partir de um endereço de IP da instituição detentora da supramencionada licença.

Ao utilizador é apenas permitido o descarregamento para uso pessoal, pelo que o emprego do(s) título(s) descarregado(s) para outro fim, designadamente comercial, carece de autorização do respetivo autor ou editor da obra.

Na medida em que todas as obras da UC Digitalis se encontram protegidas pelo Código do Direito de Autor e Direitos Conexos e demais legislação aplicável, toda a cópia, parcial ou total, deste documento, nos casos em que é legalmente admitida, deverá conter ou fazer-se acompanhar por este aviso.

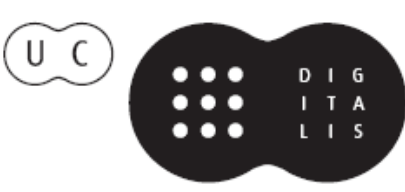




\section{OFICINAS DE \\ MUHIPITI \\ planeamento estratégico \\ património \\ desenvolvimento}

organização:

Walter Rossa

Nuno Lopes

Nuno Simão Gonçalves

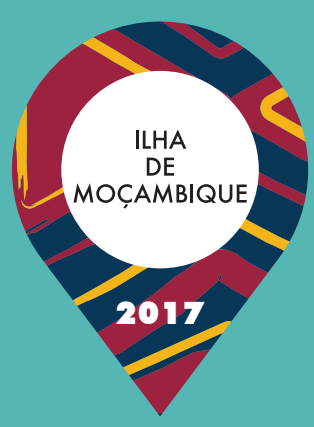




\section{SOBRE A PRESERVAÇÃO DO PATRIMÓNIO CULTURAL EDIFICADO \\ EM MOÇAMBIQUE}

Júlio Carrilho

Luís Lage

\section{INTRODUÇÃO}

Até à Independência Nacional, em 1975, alguns imóveis do património cultural e natural de Moçambique já tinham sido declarados como Monumentos Históricos. Em Maputo, através de uma portaria de 1964, tratou-se dos casos da antiga residência do Governador e da Fortaleza de Nossa Senhora da Conceição, respetivamente o atual Museu da Moeda ou Casa Amarela e a atual Fortaleza de Maputo.

No pós-independência, o primeiro passo no âmbito dos procedimentos legais para a salvaguarda do património cultural deu-se com a aprovação da Lei de Proteção do Património Cultural, em 1988, em que foram classificados os seguintes bens: todos os monumentos e elementos arqueológicos; todos os prédios e edificaç̃es erguidas em data anterior a 1920; as principais bases operacionais da Frente de Libertação de Moçambique [FRELIMO].

A Direção Nacional do Património do Ministério do Turismo e Cultura, com a colaboração da Faculdade de Arquitetura e Planeamento Físico da Universidade Eduardo Mondlane [FAPF-UEM], foram efetuando, ao longo do tempo, a recolha sistemática do património edificado das cidades e pequenos centros populacionais do país. Esta recolha foi realizada através de atividades de investigação e extensão com o objetivo de inventariar e adequar o edificado às eventuais exigências de uso pelos diversos utilizadores emergentes (municipalidades, autoridades delegadas à tutela do património, arquivos históricos, entre outros). 


\section{A VONTADE RECORRENTE DE APAGAMENTO DO PASSADO E O AFÃ DE NOVAS REFERÊNCIAS}

Transformações profundas de contexto sociopolítico, traduzidas por profundas mudanças de regime, são frequentemente acompanhadas de processos de reafirmação das novas realidades e valores que se considera importante exaltar. Estes processos de reafirmação transportam consigo algo subjacente de apagar do passado, que é sujeito de recusa. A independência de Moçambique do domínio português revelou fenómenos deste tipo, designadamente: a substituição de topónimos por todo o país; o desmonte ou derrube de estátuas e marcos de exaltação de valores, personagens ou acontecimentos históricos do colonialismo; o abandono de lugares simbólicos da afirmação colonial. Nalguns casos tais atos foram realizados de modo a, publicamente, se manifestar uma alter-individualidade que se sobrepõe a uma história de humilhação e de domínio.

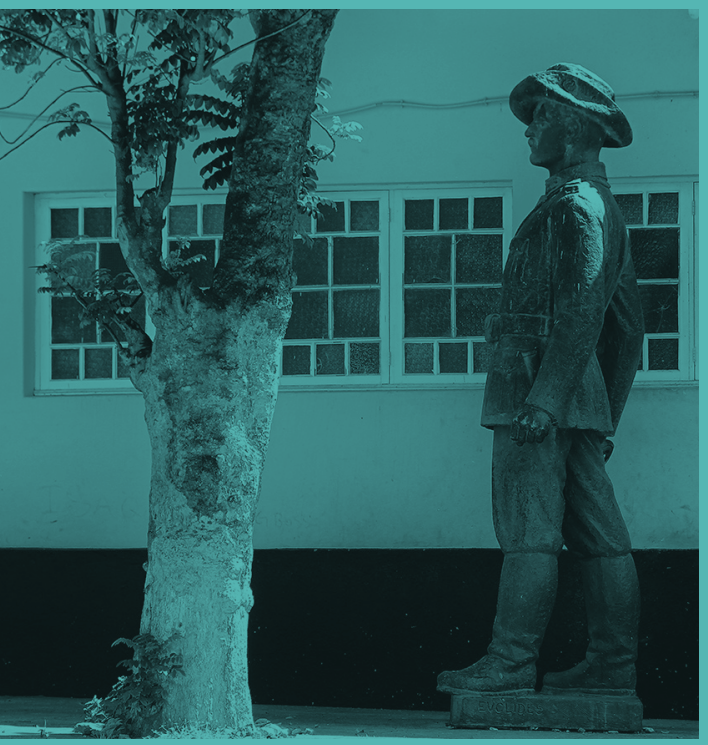

Mudar um nome ou derrubar uma estátua é mais do que uma mera substituição de personagens e símbolos urbanos, é, sobretudo, uma afirmação de novas presenças. Presenças de entidades concretas ou simbólicas que, secundarizadas durante muito tempo, renascem e se apresentam à luz do dia como valor local a ser realçado na sociedade, no tempo e no espaço. Estes processos de transformação foram rápidos, quando as lembranças subjacentes do passado eram ainda muito evidentes. É o caso das estátuas ou conjuntos esculturais em lugares centrais das cidades, sendo os exemplos mais marcantes o derrube do conjunto escultórico exaltando Mouzinho de Albuquerque, na cidade de Maputo, e do conjunto escultórico dedicado a Neutel de Abreu, na cidade de Nampula. 
Mas nem sempre o apagamento da história se fez através do derrube dos símbolos urbanos. Outra forma de afirmação da nova realidade foi a ocupação de espaços com elementos reveladores do seu uso como lugar e/ou instrumento de dominação. É o caso da transformação de espaços que foram lugares de práticas de subjugação e tortura realizadas no período colonial, em espaços de memória e exposição dessas práticas, como o caso da Vila Algarve, em Maputo, logo após à proclamação da independência.

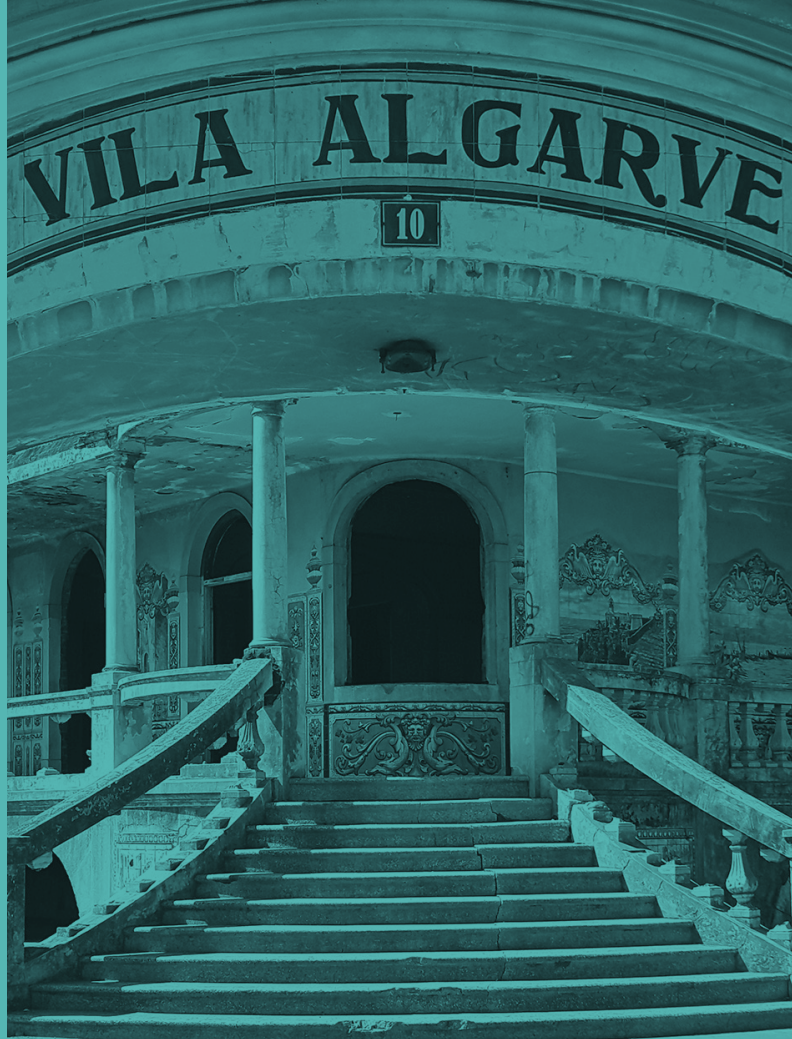

Convém referir que, no domínio do simbólico, a apropriação de espaços em que a representação não está diretamente ligada a processos de expressão de poder, não se verificaram processos de recusa ou de indiferença. Temos como exemplo os espaços de representação de natureza etnológica (Museu de Nampula) ou de carácter ambiental, ligada à fauna ou flora (Museu de História Natural de Maputo), que foram naturalmente agregados ao novo sistema de valores, mesmo quando a arquitetura exprime muito claramente valores de afirmação tipicamente colonial (neo-manuelino, Estado Novo ou, ainda, de extração popular-regionalista da metrópole), ou mesmo quando a representação etnológica do africano aparece, de forma indireta, associada à fauna, flora e costumes "bizarros" (Serra, 2015).

Um exercício esquemático da abordagem geral pós-independência pode revelar 5 períodos de ênfases relativamente distintos: (1) o período imediatamente após a declaração da independência, de 25 de junho de 1975 até 1977, no qual se verifica o abatimento dos símbolos edificados do poder colonial e se enfatiza a importância da preservação do edificado ligado à luta de libertação nacional e ao resgate de valores culturais populares intangíveis (através dos grandes festivais nacionais 
de música, canto e dança tradicionais/populares, movimento que se estendeu por todos os períodos); (2) um período curto em que se inicia o estudo e a apropriação do património edificado preexistente, procedendo-se, com naturalidade, à sua incorporação no corpus do património edificado como coisa nacional, como são disso exemplo os casos da Ilha de Moçambique e da Baixa de Maputo; (3) o período de 16 anos da guerra pós-independência, em que a governação se concentra na realidade militar, passando as preocupações de gestão do património edificado para um plano secundário; (4) o período pós Acordo Geral de Paz, assinado em Roma a 4 de outubro de 1992, em que se retomam os processos normais de gestão do país, incluindo os aspetos culturais em que se insere a problemática do património edificado. Neste período avulta de novo a necessidade de afirmação de elementos simbólicos nacionais através da presença de personagens, sítios e acontecimentos relevantes da gesta da luta pela independência - é o caso das Praças dos Heróis, das bases político-militares da luta de libertação nacional, como Matcheje (onde, em 1978, foi realizado o II Congresso da FRELIMO) - e as estátuas de Samora Machel e de outros combatentes (replicadas em praças de cidades capitais provinciais); (5) o último período, incluindo o presente, é caracterizado por uma busca mais aprofundada de definição do património cultural edificado, centrado nos processos metodológicos específicos, de negociação e consciencialização, que inclui as etapas de levantamento, inventariação, registo, legitimação e divulgação em que se enquadram várias publicações. A urgência da afirmação de novos símbolos edificados endógenos para a nova realidade pós-independência, condicionada pela falta de tempo e tradição nos processos da sua definição (conceção, legitimação, projeto e construção), levou a que se instalassem atitudes de repetição, de inspiração e cópia direta do que se produzia na capital do país. Isto evidencia que, no domínio da criação de novas referências simbólicas nacionais de património edificado e espacial urbanos, se está ainda numa fase embrionária de aprendizagem, caracterizada por comportamentos locais de mimetização face aos escalões mais altos de decisão, capital ou governos central e provincial, por vezes sem intervenção local. 


\section{UMA CONSTRUÇÃO COLETIVA REITERADA PELOS ANTIGOS EX-PROPRIETÁRIOS COMO SUA}

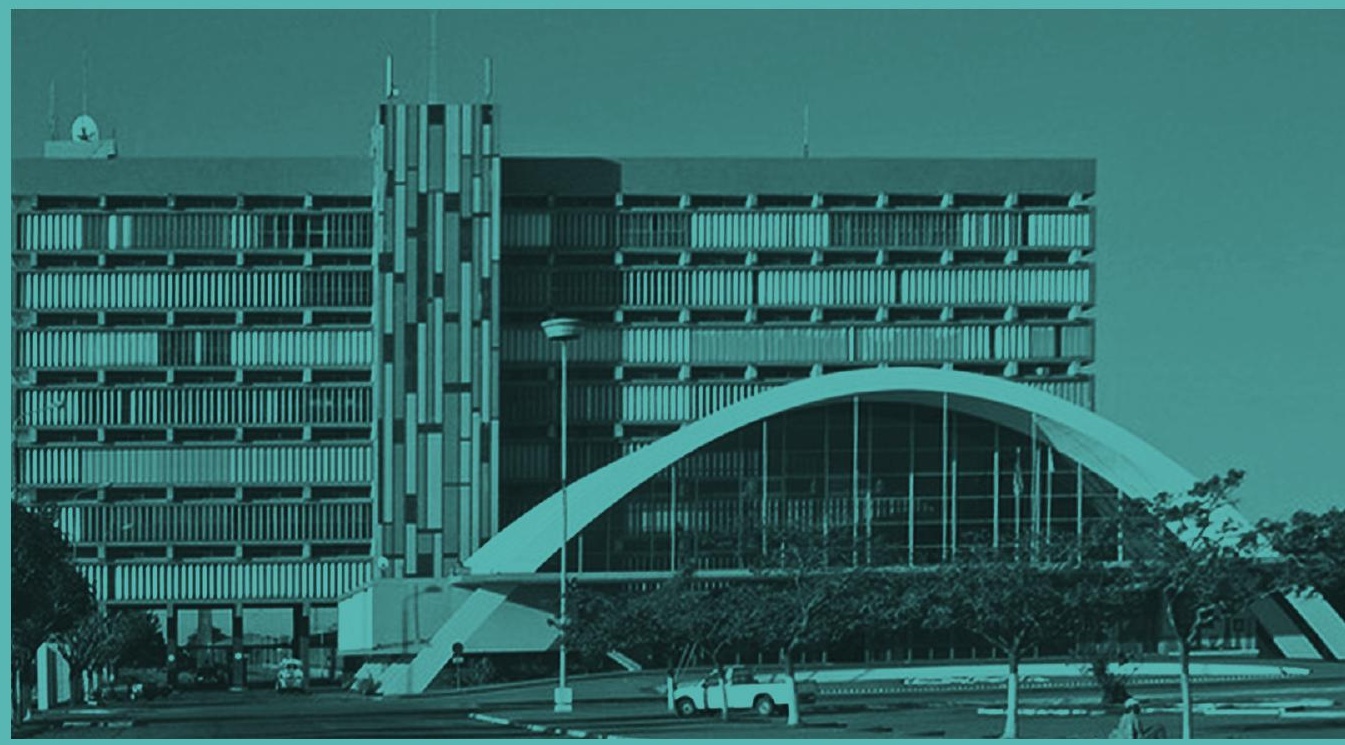

Relativamente aos estudos ligados à herança arquitetónica, avulta a ideia errónea de que o que foi construído no período colonial é legado do colonialismo, é património do colonizador e, em última análise, produto e pertença de outrem. Estamos num campo em que os próprios teóricos de arquitetura contemporâneos dos países outrora dominadores reclamam para a sua cultura os louros da originalidade das abordagens espaciais, de qualidade inquestionável, de objetos construídos em território estranho à sua metrópole. Quer dizer: os construtores são apenas vistos como meros instrumentos da realização de uma ideia; o clima, a realidade ambiental, os desafios do território são apenas factos técnicos; os contrastes de luz, o apelo da cor, o carácter icónico dos objetos, os simbolismos iconográficos do imaginário popular, são apenas fruto do exercício de descoberta e da genialidade dos projetistas do tempo colonial, sem nada que os ligue à natureza, às vontades e às culturas em que os objetos se inserem na contemporaneidade. A visão do outro é fruto de uma espécie de cegueira quanto à sua existência. Assim, torna-se impossível a reclamação da propriedade desses bens por quem os construiu, a compreensível apropriação pelos que possibilitaram 
a sua existência, pelos que os possuem como propriedade sua e nacional. É provável que também daqui resulte a dúvida quanto à pertinência histórica da sua conservação e valorização como património nacional dos países em construção e afirmação. É por isso que o exercício e a apropriação desse património edificado, que a nível académico tanto se defende, se transforma num exercício muito condicionado pela política, pelas perceções das elites, pelas dinâmicas das forças em presença, por vezes feitos à margem dos critérios de qualidade, inovação e de contribuição para o futuro que esses objetos podem constituir para a sociedade e gerações vindouras.

\section{A PERSUASÃO DA MODERNIDADE}

O levantamento de elementos da arquitetura popular permitiu constatar o impacto da imagem do moderno, não apenas nas periferias das cidades, mas também em pleno contexto rural. No contexto rural, a imagem do que é moderno, também associada à ideia do novo, vai ser apropriada pelos moradores a partir da cidade moderna. Vai-se buscar à forma a ideia de modernidade a adotar na arquitetura, muitas vezes sem se ter acesso aos materiais e a outros elementos que a conformam no contexto urbano. A dimensão do construído e a utilização da linha direita fascinam como novidade num ambiente de formas orgânicas e, frequentemente, de natureza curvilínea. Nas periferias das cidades, os elementos construtivos (como as lajes e as palas de proteção em betão e os elementos de ventilação e as varandas) são usados como elementos decorativos ou da busca de segurança e durabilidade. Se no âmbito político se reafirma a necessidade, de certo modo passadista, de se buscar a inspiração na arquitetura rural como elemento de identidade e afirmação da nossa tradição, os construtores dos objetos da arquitetura vão buscar os exemplos de como fazer, precisamente na forma, nos materiais e técnicas exógenas. É no equilíbrio entre o mais adequado e apropriado, o mais durável e económico, a tradição e a modernidade, que se trava a batalha da transformação da arquitetura popular naquilo que se percebe como sendo a afirmação da superioridade da arquitetura moderna. 


\section{O DESAFIO DO USO}

O uso dos espaços está intimamente ligado à carga cultural de quem os concebe e daqueles que deles se apropriam. A desconexão e tensão entre estes sujeitos pode conduzir a incompatibilidades de uso com efeitos negativos na manutenção e na durabilidade do edificado. É verdade que há uma dimensão económica no binómio projetouso, mas parece não haver dúvida de que os modos de vida que os usuários transportam consigo têm uma grande importância na eficácia da apropriação das propostas de espacialidade disponíveis.

O objetivo político de contrariar a segregação urbana do período colonial foi, em parte e momentaneamente, alcançado com a ocupação da cidade pela população indiferenciada, independentemente da natureza socioeconómica dos novos moradores, quer eles fossem provenientes das áreas pericentrais marginalizadas, quer fossem oriundos do mundo rural (sobretudo através da lei da nacionalização dos prédios de rendimento, em 1976). Este fenómeno de disfuncionalidade entre a cidade desocupada e os seus novos moradores foi sendo corrigido pela reversão da nacionalização dos imóveis de rendimento, em 1991 (Decreto $n^{\circ} 2 / 91$ ), e da atividade

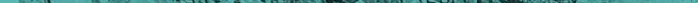


do mercado, permanecendo um desajuste em muitos casos. Um dos resultados desta disfuncionalidade é o envelhecimento precoce do edificado, que atinge também edifícios de grande valor patrimonial arquitetónico, bem como o impacto negativo da valorização dos espaços em que eles estão inseridos no conjunto urbano, e que conduz à sua destruição e substituição por edificações com resultados económicos imediatos mais apetecíveis. Isto é potenciado por uma perceção em que muitas vezes está ausente o imperativo de proteção desse património, frequentemente associado a uma realidade de sofrimento que ninguém quer ver repetido historicamente.

Num contexto de grande volatilidade e de rápidas transformações, valia a pena ponderar-se se a única atitude de preservação do património deveria limitar-se a garantir a sua sobrevivência como elemento da paisagem urbana, ou se se poderia recorrer a outros métodos que assegurassem a permanência da sua memória, ou seja, resgatá-lo da sua morte excecional quando for impossível manter fisicamente o bem edificado. Um exemplo interessante desta abordagem pode ser dado pelo seguinte facto: há alguns anos um edifício que era geralmente considerado como tendo valor patrimonial foi destruído pelo concessionário do terreno, muito bem localizado, em que ele estava inserido. As autoridades da Cultura com tutela, bem como a imprensa, deram destaque ao caso, mas já não era possível repor o edifício. Qual foi a atitude tomada? Foi a de persuadir o novo concessionário a considerar este facto, criticado geralmente pelos círculos conservacionistas, e, no projeto para o edifício de rendimento a erigir no local, considerar um espaço de memória com acesso ao público, em que se reproduzisse tecnicamente o edifício demolido, contratando para o efeito uma equipa especializada que procedesse ao seu levantamento e execução rigorosos de uma maqueta. No caso, similar, do novo edifício-sede da administração aduaneira, localizado no limite do conjunto protegido da Baixa de Maputo, esta prática já tinha sido ensaiada com resultados positivos, tendo o promotor financiado o levantamento rigoroso do conjunto urbano, que teve de se demolir e que foi realizado sob a direção da FAPF-UEM. 


\section{O DESAFIO DA APROPRIAÇÃO}

Em relação ao património cultural edificado de Moçambique, a sensibilidade institucional que se tem vindo a construir, em particular junto do Ministério da Cultura e, por extensão, junto dos responsáveis por este assunto ao nível das instituições governamentais, permitiu, entre outras ações, que se tivesse conseguido:

- a elevação da Ilha de Moçambique à qualidade de conjunto edificado a proteger;

- $\quad$ a proteção do conjunto edificado da Baixa de Maputo;

- a criação do Conselho Nacional do Património Cultural para, numa situação em que se verificam muitas lacunas legais e regulamentares, aconselhar os órgãos do Estado sobre matérias especializadas no âmbito da preservação do património cultural tangível e intangível;

- a realização de várias conferências nacionais dedicadas a assuntos culturais, em que se discutiu a preservação do património cultural, como o património edificado, a ser um dos temas tratados;

- a criação no Ministério da Cultura de um departamento especificamente dedicado à problemática da preservação do edificado no quadro do património cultural;

- a permanente articulação com a FAPF-UEM no que respeita à análise, qualificação, salvaguarda, proteção e regulamentação do património edificado, tendo a faculdade colaborado na redação da Lei de Proteção do Património Edificado e do Regulamento dos Bens Classificados na llha de Moçambique, recentemente (2016) aprovados pelo Conselho de Ministros;

- a realização de seminários multidisciplinares com especialistas de diversas áreas do conhecimento, bem como de pessoas notáveis e cidadãos interessados, para se promover a inventariação, seleção e eleição de edifícios com valor patrimonial a destacar, através de um sistema de discussão e votação; seminários deste tipo foram realizados em Maputo, Beira, Ilha do Ibo e llha de Moçambique.

Este tipo de intervenção, com o patrocínio ou anuência das autoridades pertinentes, permite elevar a consciência do valor do património edificado, assinalar a importância da sua salvaguarda, proteção e valorização e, principalmente, a apropriação e gradual empatia com o edificado a proteger. 


\section{O DESAFIO DO SENTIDO DE PERTENÇA}

O sentido de pertença é um dos fios que tece o pano de fundo de perceções e problemas que enquadram, encorajam ou limitam a discussão da problemática do património cultural em Moçambique. Por exemplo: 1) para alguns, salvaguardar o património tangível referente à presença colonial pode ser considerado desnecessário por não se estar confortável com essa realidade desqualificante que se sente não ser nossa. A verdade é que os elementos tangíveis criados nesse período representam processos complexos, por vezes únicos, de interação ao longo da história, sendo claramente justificada a sua preservação (DNPC, 1993: 2). Quer dizer, o dever de preservação do património refere-se não apenas àquilo que se considera pertencer ao país, mas também a bens de valor que, percebendo-se como sendo alheios, se imbricaram na realidade nacional, ficando à responsabilidade dos moçambicanos; 2) para outros, a recuperação de património tangível autóctone com maior grau de efemeridade, nomeadamente construções e objetos de materiais naturais, é também desnecessária pela dificuldade que isso representa e porque se trataria de agir sobre uma realidade precária e em constante mudança que, mesmo sendo importante para compreender o que virá no futuro, é demasiado oneroso e complexo. A este propósito convém, no entanto, referir a Carta de Veneza (1964) que, logo no seu primeiro artigo, postula que o conceito de monumento histórico se aplica não apenas a grandes obras mas também a obras modestas do passado que adquiriram significado cultural.

É recorrente a discussão da problemática do sentido de pertença, no âmbito do património cultural, desembocar na questão de "quem é o possuidor do passado?" (apud Egan, 2010). Nalguns debates que se têm feito no país, alguns participantes de círculos diferenciados da sociedade sugerem que uma maior consciencialização neste domínio poderia facilitar a definição e aplicação de políticas sustentadas de salvaguarda e conservação do património edificado. É provável que a presença, ainda fresca, das lembranças dos processos dolorosos de dominação e discriminação coloniais explique muitas das reticências, alguma indiferença, um certo oportunismo e a falta de empatia que por vezes se verifica entre alguns dos moçambicanos perante o património originado nesse período conturbado da história do país. 


\section{QUESTÕES METODOLÓGICAS}

Partindo de uma abordagem transversal, o método utilizado definiu-se pelas condições disponibilizadas e pelos recursos existentes no país, tendo como objetivo a chegada de consensos para a apresentação de propostas de classificação de determinados edifícios de Maputo e da Beira aos seus respetivos Conselhos Municipais. Adotaram-se, assim, as seguintes etapas:

- definição das equipas de trabalho e chefias, efetuado pela FAPF-UEM;

- inventariação preliminar dos edifícios que constituiriam o universo da amostra sobre a qual se trabalharia, e reunião preparatória de toda a informação disponível de interesse;

- seleção expedita dos edifícios considerados;

- recolha preliminar de informação bibliográfica e iconográfica visando a caracterização geral dos edifícios selecionados na amostragem preliminar;

- visitas de campo para testar as hipóteses colocadas, com levantamentos arquitetónicos e iconográficos complementares feitos por equipas técnicas qualificadas;

- definição hipotética de uma lista restrita de edifícios a salvaguardar;

- preparação do dossier a ser submetido aos consultores durante os seminários multidisciplinares de consulta pública;

- preparação dos seminários multidisciplinares de consulta pública;

- realização dos seminários de consulta para apresentação, análise e discussão dos critérios e das opções preliminares estabelecidas com vista à definição final do universo da amostra;

- definição por consenso ou votação da lista estrita de edifícios selecionados a proteger, na base de um número reduzido de edificações ou objetos urbanos definidos após consultas multidisciplinares do processo preliminar. 


\section{- Regulamento sobre a Gestão de Bens Culturais Imóveis}

A FAPF-UEM colaborou com o Ministério da Cultura, prestando apoio na elaboração do Regulamento sobre a Gestão de Bens Culturais Imóveis aprovado pelo decreto 55/2016 de 28 de novembro de 2016. O regulamento visa a classificação, proteção adequada, conservação e gestão sustentáveis dos bens culturais imóveis, sendo estes estruturados consoante o seu valor relativo nas seguintes classes:

- A+, património e bens culturais do Estado Moçambicano com categoria de Património Mundial com valor universal excecional;

- A, património e bens culturais de valor elevado nacional, incluindo aqueles que têm o potencial de contribuir significativamente para objetivos de pesquisa e investigação nacional;

- B, património e bens culturais de valor médio local, incluindo aqueles que têm o potencial de contribuir significativamente para objetivos de pesquisa e investigação local;

- C, património e bens culturais de valor limitado local, incluindo aqueles que têm o potencial de contribuir para os objetivos de pesquisa e investigação no âmbito local;

- D, património e bens culturais de limitado valor individual relativo, que, como parte de um contexto ou conjunto mais vasto, contribui positivamente para o carácter do ambiente urbano ou rural local em que se insere. Incluem-se neste contexto bens que apresentem um uso característico de desenho, técnicas e materiais de um período ou tipo particulares de edificação.

O Regulamento define também os níveis de intervenção para cada uma das classes, assim como a criação de Comissões de Gestão de Bens Culturais Imóveis, com o objetivo de garantir a proteção do património cultural pelas comunidades locais, como legítimos guardiões e beneficiários. 


\section{- Plano de Urbanização da Vila do Ibo}

Este plano foi elaborado em 2008, através de um contrato entre a Direção Provincial para a Coordenação da Ação Ambiental de Cabo Delgado e a FAPF-UEM. A importância deste plano justificava-se pelo valor patrimonial, histórico e cultural da llha do Ibo e das Quirimbas. Preconizaram-se ações de restauro de conservação para todos os edifícios monumentos através da reposição do seu estado original, com eventuais melhorias ou modernizações das suas funcionalidades e de ações de reabilitação, com ou sem refuncionalização, mantendo-se a imagem e o traçado originais no exterior, optando-se, quando necessário, por processos de modernização em tecnologias e materiais, de modo a garantir maior longevidade e conforto.

O regulamento do plano define também as normas para a recomposição do tecido urbano, a manutenção da escala humana típica do conjunto edificado da vila, o respeito pela criação de espaços de transição entre a rua e o espaço interior através do sistema de varandas com colunatas, a manutenção da simetria das fachadas, a preferência pela cobertura em telha e também o uso, nas fachadas, de paletas cromáticas coerentes com a cor do conjunto.

O regulamento procura também restringir, de uma maneira geral, o uso de certos materiais locais que se traduzam em destruição, a prazo, de recursos naturais com impacto negativo no equilíbrio ecológico insular.

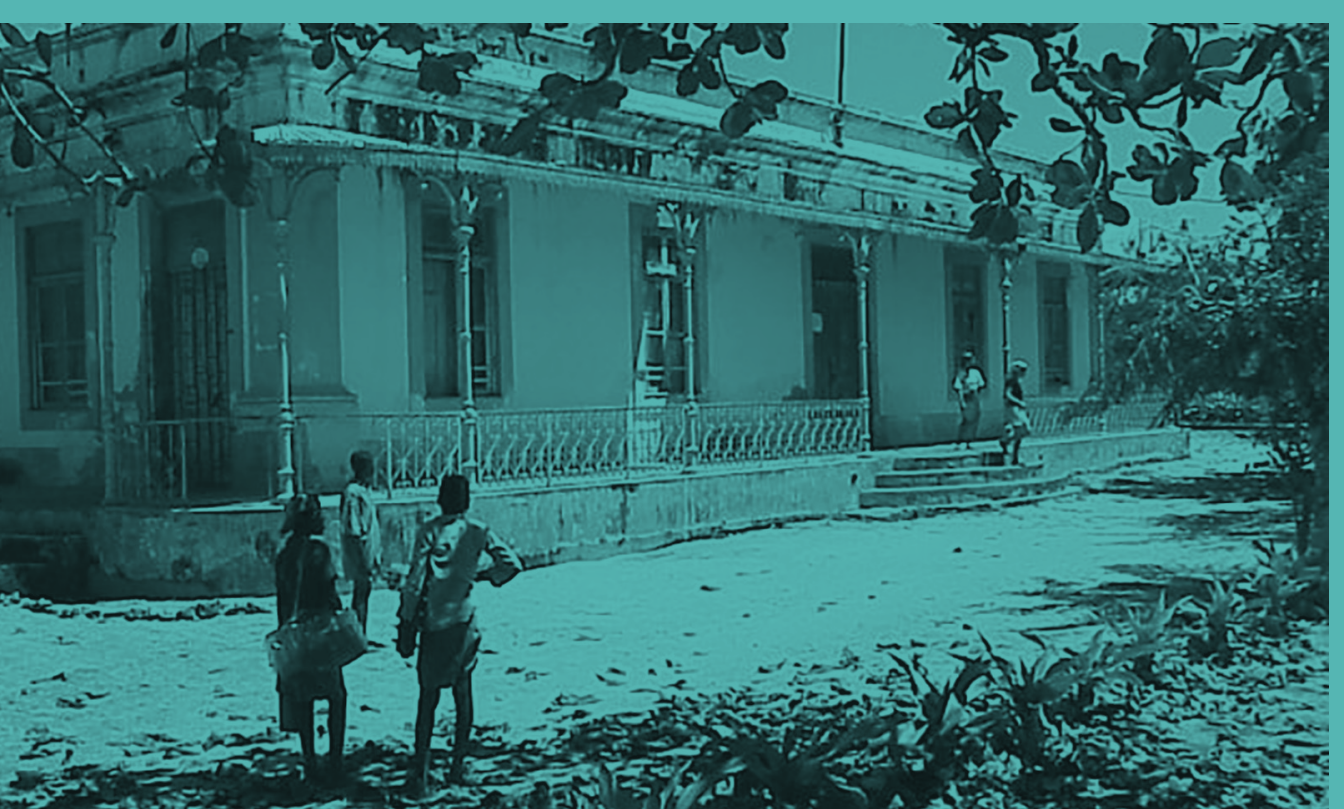




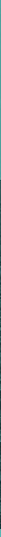

\section{- Plano Parcial de Urbanização da Baixa de Maputo}

Este plano foi executado em 2015 pelo Conselho Municipal de Maputo e o consórcio entre a Cardno Emerging Markets, a Design Convergence Urbanism e a FAPF-UEM.

Tendo em conta esse fator, o crescimento rápido da cidade e uma vez que o tecido histórico de ruas residenciais, edifícios e espaços públicos fornecem à cidade o seu carácter distinto, procurou-se estabelecer, através da regulamentação do plano, uma agenda imediata para a sua preservação. O plano classificou 314 edifícios distribuídos pelas classes estabelecidas pelo Regulamento sobre a Gestão de Bens Culturais Imóveis. O regulamento define duas zonas delimitadas de proteção: a do núcleo inicial da cidade e a industrial. Novas intervenções deverão garantir o respeito pelas delimitações e padrões dos talhões existentes, pelo carácter e pela escala das fachadas dos quarteirões e do edificado na envolvente dos bens históricos classificados individualmente, e pelas cérceas definidas nas respetivas fichas de ordenamento do plano. Preconiza também as linhas de vista-mar, através das vias da malha urbana no núcleo inicial da cidade, impedindo a sua obstrução. Foram também designadas interconexões especiais de praças da zona da Baixa, através das vias de circulação, relacionando as suas três principais praças de épocas diferentes. Qualquer nova intervenção deverá respeitar e realçar a composição planeada da malha, incluindo o traçado arquitetónico predominante, e garantir que sejam de materiais apropriados ao carácter do espaço. O Regulamento confere ainda destaque aos espaços públicos com interesse patrimonial. 


\section{- Regulamento sobre Classificação e Gestão do Património Edificado e Paisagístico da Ilha de Moçambique}

Por contratação do Ministério da Cultura através do Conselho Nacional do Património Cultural, a FAPF elaborou, em 2014, o Regulamento sobre Classificação e Gestão do Património Edificado e Paisagístico da llha de Moçambique, aprovado pelo Decreto 54/2016 de novembro de 2016. Foram classificados 510 edifícios de pedra e cal, estabelecendo-se que qualquer intervenção sobre o património edificado da cidade da Ilha de Moçambique deverá obedecer aos critérios gerais de autenticidade, integridade, legibilidade, reversibilidade, identidade cultural e ambiental do edificado preexistente. Estes critérios deverão ser considerados nos processos de intervenção, no conjunto ou isoladamente, relativamente aos processos de requalificação do edificado no contexto urbano, aos diferentes elementos construtivos, salvaguardando o traçado original aparente dos edifícios e das fachadas, e respeitando a escala e a continuidade de desenho de imagem.

Neste regulamento deu-se também importância, tal como na llha do Ibo, ao uso dos materiais para a conservação e restauro, devendo ser preferencialmente originais ou precedentemente aplicados para as construções de pedra e cal, abrindo a possibilidade, em novas construções, de introdução de materiais diferentes sempre que se respeite o espírito do lugar.

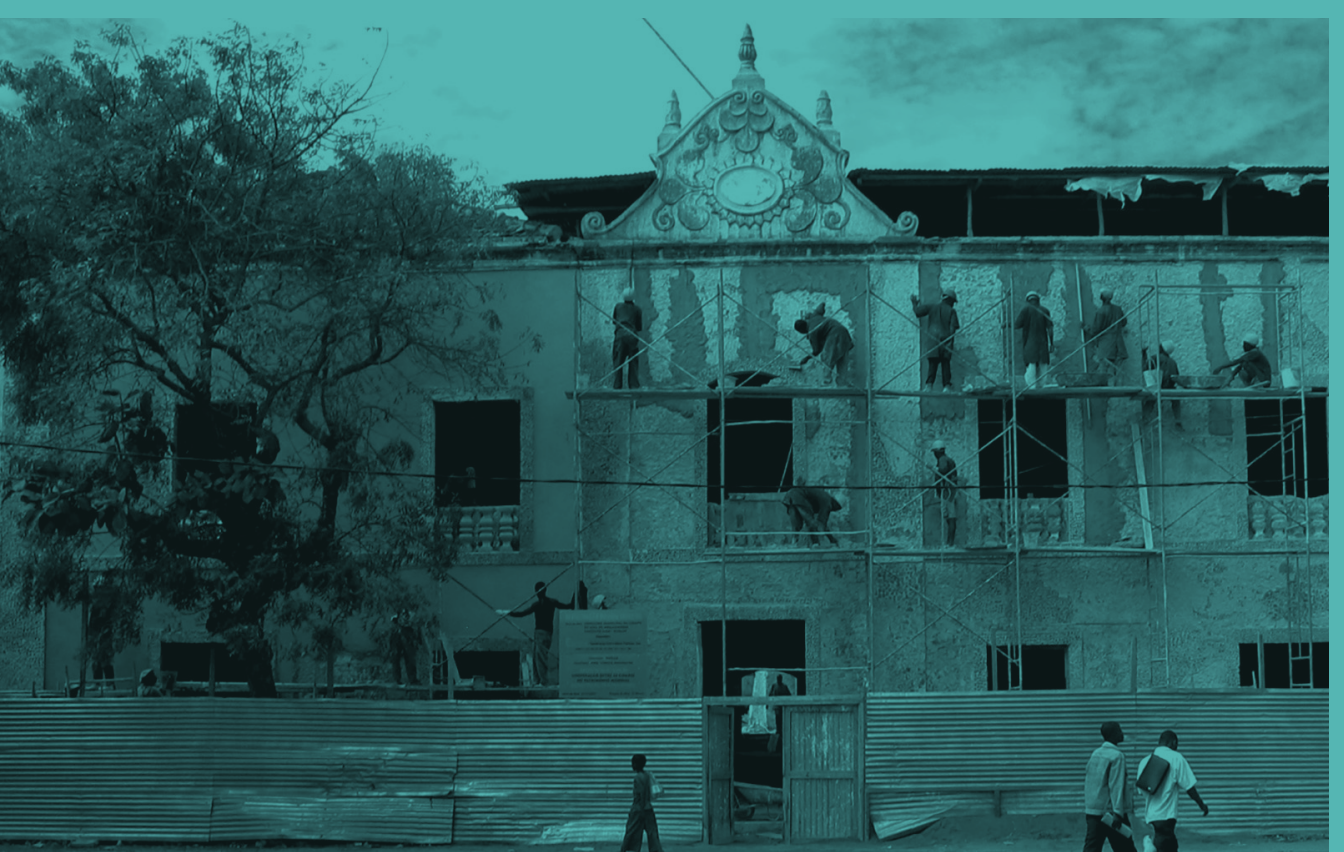




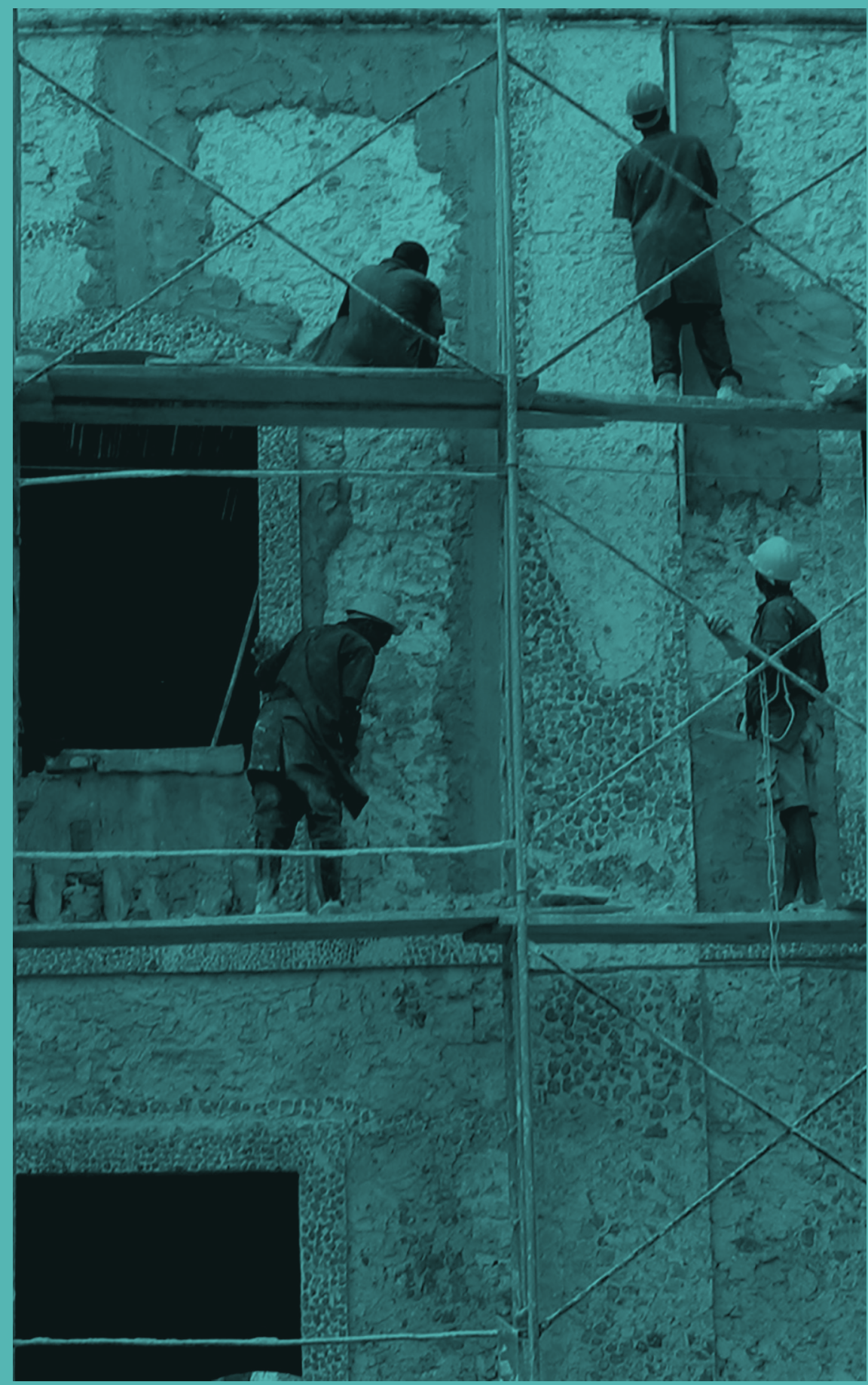




\section{CONCLUSÕES PRELIMINARES}

Os principais desafios que Moçambique enfrenta estão ligados à formação e treino nas práticas de preservação e conservação, à elevação das capacidades institucionais para o estudo, regulamentação e monitorização, bem como ao estabelecimento de mecanismos de envolvimento dos diferentes tipos de agentes económicos e sociais, incluindo os proprietários individuais de edifícios com valor patrimonial. Mas também à carência de fundos dedicados ao estudo, salvaguarda, preservação e manutenção do património; à consciencialização e educação permanente do público para a importância do património edificado; à descentralização regulada de atividades, com a consequente elevação do significado do sentido de pertença, de partilha coletiva e de sustentabilidade em relação às atividades ligadas à preservação do património cultural, incluindo o edificado.

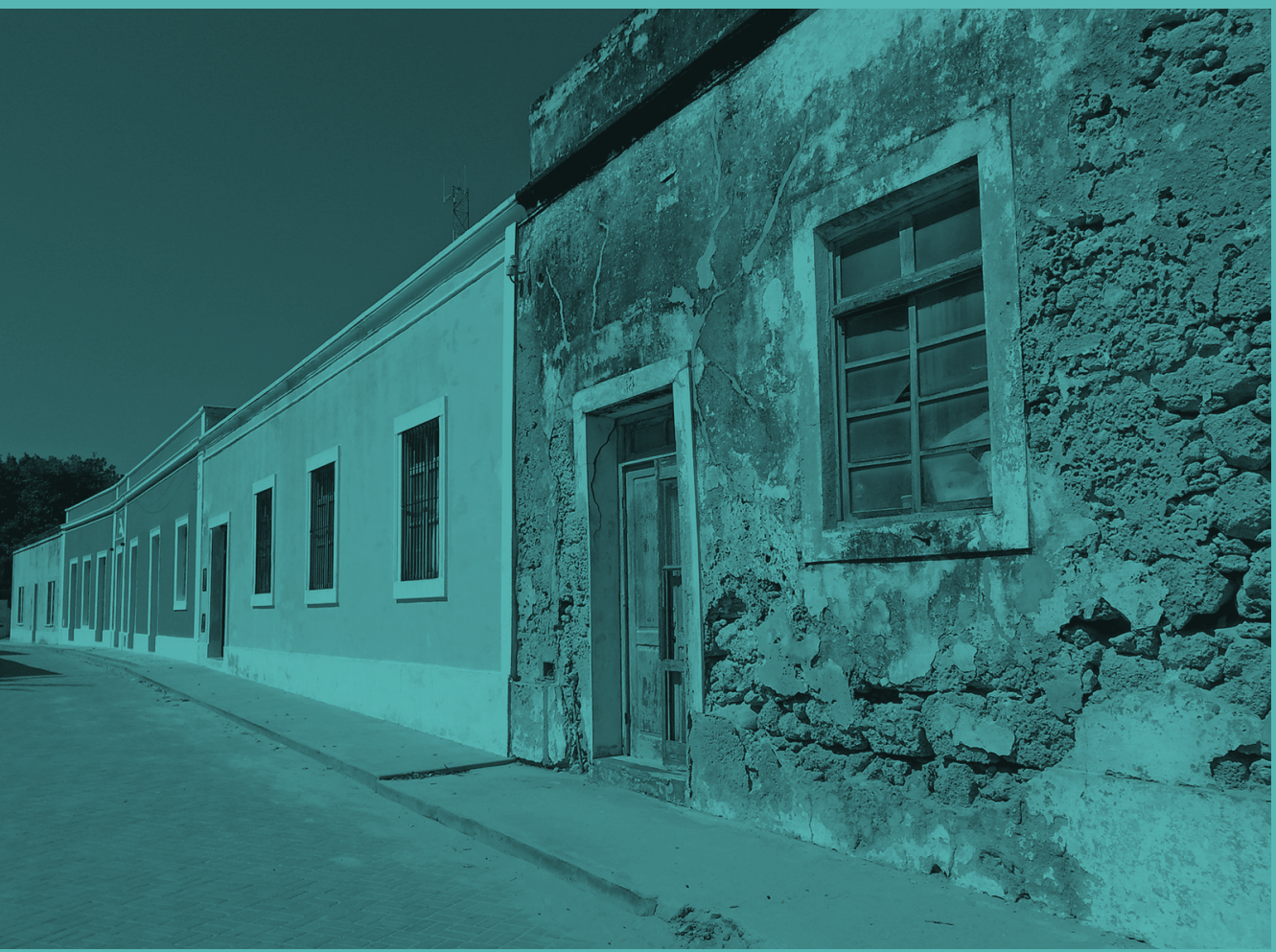


Como estratégia integrada de salvaguarda e preservação do património cultural é ainda importante referir, de forma sintética, a experiência indiana, cujos cinco princípios foram expressos por Ambika Soni (2008), respetiva Ministra da Cultura e Turismo, que aqui partilhamos:

$1^{\circ}$ o património é um recurso e um activo valioso. Não há contradição entre a preservação do património e o desenvolvimento; $\mathbf{2}^{\circ}$ uma parceria entre a sociedade civil, em geral, e as comunidades locais pode ajudar a criar apego e sentido de pertença quanto ao património e à sua preservação. A educação e o trabalho de consciencialização são instrumentos valiosos para tal; $\mathbf{3}^{\circ}$ a mitigação das carências financeiras exige abordagens criativas e determinadas. A criação de parcerias de diversas naturezas, nomeadamente público-privadas pode ser um caminho fecundo, envolvendo-se instituições públicas, empresas e outro tipo de organizações na angariação de fundos para atividades conjuntas de preservação do património, bem como a criação de um Fundo Nacional para o património Cultural que acolha tais iniciativas pode ser uma via; $4^{\circ}$ o papel fundamental do governo deve centrar-se no desempenho do seu papel de catalisador da atividade de preservação do património, através de políticas e medidas legislativas adequadas, bem como de mecanismos de controlo e preservação dos monumentos e sítios não protegidos e em perigo; $\mathbf{5}^{\mathbf{0}}$ a escassez de especialistas e mão-de-obra no domínio da preservação e da gestão dos recursos culturais exige a tomada de medidas específicas de capacitação institucional e de formação especializada.

Nenhum destes princípios de estratégia está em contradição com aquilo que está definido para o país (Macamo, 2009). Trata-se de consolidar, completar, articular, operacionalizar e tornar sustentável o processo, através dos mecanismos legais adequados, bem como através da divulgação e participação do máximo de atores interessados.

Um elemento importante no âmbito da preservação do património edificado é a dimensão colaborativa que se consiga obter, fazendo com que, para além do Estado, participem igualmente organizações da sociedade civil, empresas públicas e privadas, associações, grupos 
de cidadãos e outros. Isto permite descentralizar as atividades de salvaguarda e proteção, reservando-se às instituições do Estado o papel regulador, promotor, mediador, encorajador e, inclusivamente, de premiação das iniciativas autorizadas de preservação do património cultural pelos diferentes agentes sociais.

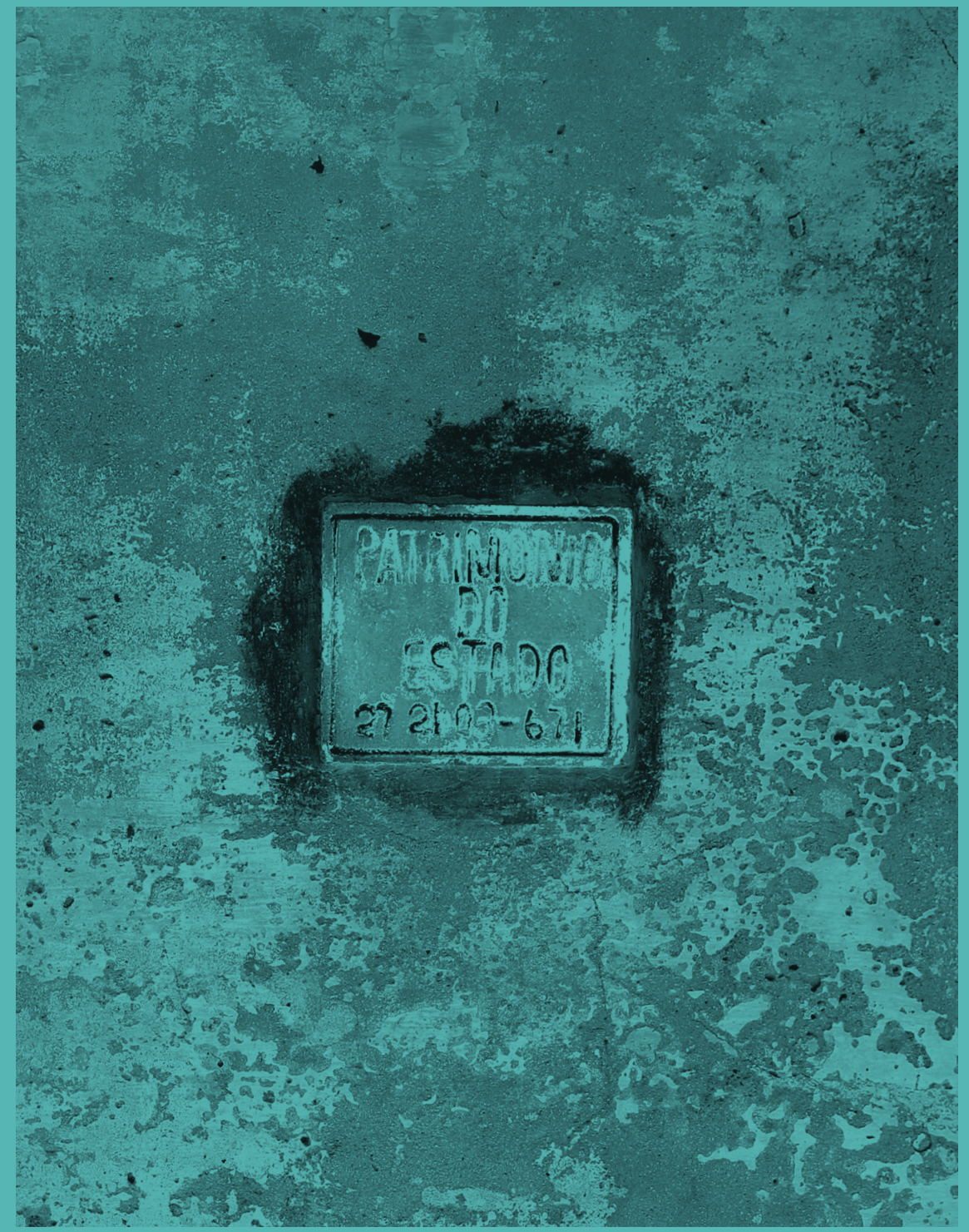




\section{REFERÊNCIAS BIBLIOGRÁFICAS}

BATTLE, Stephen; STEEL, Tony (2001), Conservation and Design Guidelines for Zanzibar Stone Town. Tanzania: Aga Khan Trust for Culture e Unesco, Relatório/manual de boas práticas. Consultado a 20.03.2009, em http:// www.archnet.org/library/documents/one-document.jsp?document_ $i d=9483$.

BELTRÃO, Ana Raquel (2002), "Patrimônio cultural: novas fronteiras", Prim@ Facie, ano 1, n. ${ }^{\circ}$ 1. Consultado a 03.04.2009, em http://www.estig. ipbeja.pt/ ac_direito/artigo_3.pdf.

BRUSCHI, Sandro; SONDEIA, Benjamim (coords.) (2003), Inhambane: elementos de história urbana. Maputo: Edições FAPF, Universidade Eduardo Mondlane

CARRILHO, Júlio (2005), Ibo, A casa e o tempo. Maputo: Edições FAPF, Universidade Eduardo Mondlane.

CARRILHO, Júlio et al. (2000), Um Olhar para o habitat informal moçambicano: de Lichinga a Maputo. Maputo: Edições FAPF, Universidade Eduardo Mondlane.

CARRILHO, Júlio et al. (2005), Era uma vez uma palhota... História da casa moçambicana. Maputo: Edições FAPF, Universidade Eduardo Mondlane.

CHAVEZ, Roberto et al. (2002), Cultural Heritage \& Slum Upgrading. World Bank's Experience and good Practice. Massachussetts: MIT.

COSTA, Aline de Caldas (2007), Reflexões sobre Cultura e Bens Simbólicos: abordagens sobre produção cultural e poder social. Trabalho apresentado no III ENECULT - Encontro de Estudos Multidisciplinares em Cultura, realizado entre os dias 23 a 25 de maio de 2007, na Faculdade de Comunicação/UFBa, Salvador, Brasil. Consultado a 05.04.2009, em: www.cult.ufba.br/enecult2007/AlinedeCaldasCosta.pdf.

Decreto n. ${ }^{\circ}$ 54/2016, de 28 de novembro que aprova o Regulamento sobre a Classificação e Gestão do Património Edificado e Paisagístico da Ilha de Moçambique. Boletim da República n. ${ }^{\circ} 142$.

Decreto n. ${ }^{\circ}$ 55/2016, de 28 de novembro que aprova o Regulamento sobre a Gestão de Bens Culturais Imóveis. Boletim da República n. ${ }^{\circ} 42$ (I).

Direcção Nacional de Património Cultural (1993), Definição de Procedimentos inerentes à Protecção do Património Edificado Classificado. Maputo: Ministério da Cultura e Juventude, Direcção de Monumentos e DNPC (documento orientador, de 30 de junho de 1993, com matéria ainda 
não legislada).

EGAN, Valerie (2010), Post-Colonial Politics and Cultural Heritage. Egyptian Repatriation Requests and European Museums, Master's Research Capstone. Oregon: University of Oregon.

FERNANDES, José Manuel (coord.) (2011), África. Arquitectura e Urbanismo de Matriz Portuguesa. Lisboa: Caleidoscópio e Universidade Autónoma de Lisboa.

FONSECA, Alice Registro; DÓRIA, Renato Palumbo (2008), Definindo o valor histórico: uma reflexão sobre património. Consultado a 05.04.2009, em http://www.ic-ufu.org/anaisufu2008/PDF/IC2008-0089.PDF.

FREY, Pierre (2010), Learning from Vernacular. Towards a New Vernacular Architecture. France: Actes Sud.

FRONER, Yacy Ara (2002), Patrimônio Histórico e modernidade: construção do conceito a partir da noção de revitalização de sítios, monumentos e centros urbanos. Consultado a 04.04.2009, em: http://www.patrimoniocultural.org/OLINDA2002/TRABALHOSSIMPOSIO/ YACYARAFRONER.HTML

GRAHAM, Brian; HOWARD, Peter (eds.) (2008), The Ashgate Research Companion to Heritage and Identity. England and USA: Ashgate Publishing Limited.

ICOMOS (1972), Resolutions of the Symposium on the introduction of contemporary architecture into ancient groups of buildings. Budapest: 3rd ICOMOS General Assembly.

LAGE, Luís et al. (coords.) (2010), Inventário do Património Edificado da Cidade de Maputo - Catálogo de Edifícios e Espaços propostos para Classificação. Maputo: Edições FAPF, Universidade Eduardo Mondlane.

LAGE, Luís et al. (2012), Maputo - Património Arquitectónico. Lisboa: Caleidoscópio.

LAGE, Luís et al. (2013), Beira - Património Arquitectónico. Lisboa: Caleidoscópio.

Lei n. ${ }^{\circ}$ 10/88 de 22 de dezembro, que determina a proteção legal dos bens materiais e imateriais do património cultural Moçambicano. Boletim da República $n{ }^{\circ} 50$ (I).

LINO, Raul (1992), Casas Portuguesas. Alguns Apontamentos sobre o Arquitectar das Casas Simples. Lisboa: Edições Cotovia.

LIRA, Sérgio (1999), Políticas museológicas e definição do conceito de Património: da norma legislativa à prática dos museus. Águas Santas. 
Consultado a 15.04.2009, em

http://www.ufp.pt/slira/artigos/coloquioapomnov99.htm.

LOPES, Flávio (2012), Património Arquitectónico e Arqueológico. Noção e Normas de Protecção. Lisboa: Caleidoscópio.

LOPES, Flávio; CORREIA, Miguel Brito (2014), Património Cultural. Critérios e Normas Internacionais de Protecção. Lisboa: Caleidoscópio.

MACAMO, Solange (2009), Politica de monumentos. Proposta. Maputo: Conselho de Ministros.

MENEGUELLO, Cristina (2000), A preservação do patrimônio e o tecido urbano. Parte 1. A reinterpretação do passado histórico (1). Consultado a 13.09.2017, em

http://www.vitruvius.com. br/arquitextos/arq000/esp007.asp.

Ministério da Educação e Cultura/ Direcção Nacional de Património Cultural

(2008), Classificação do Património Cultural Nacional. Maputo:

Ministério da Educação e Cultura e DNPC (documento em discussão).

Ministério da Educação e Cultura/ Direcção Nacional de Património Cultural (2009), Política de Monumentos. Maputo: Ministério da Educação e Cultura e DNPC (documento em discussão).

Plano de Urbanização da Vila do Ibo (2008). Pemba: Governo da Província de Cabo Delgado.

Plano Parcial de Urbanização da Baixa de Maputo (2015), Regulamento de Protecção de Bens Culturais Imóveis. Maputo: PROMAPUTO II.

ROSSA, Walter (2015), Fomos Condenados à Cidade. Uma década de Estudos Sobre Património e Urbanismo. Coimbra: Imprensa da Universidade de Coimbra.

ROSSA, Walter; RIBEIRO, Margarida Calafate (orgs.) (2015), Patrimónios de Influência Portuguesa: modos de olhar. Coimbra, Lisboa e São Paulo: Imprensa da Universidade de Coimbra, Fundação Calouste Gulbenkian e Editora da Universidade Federal Fluminense.

Secretaria de Estado da Cultura de Moçambique; Arkitektskolen i Ãrhus, Danmark (1986), Ilha de Moçambique, relatório - Report. Moçambique e Dinamarca: Secretaria de Estado da Cultura e Arkitektskolen i Ãrhus. SERRA, Carlos (2015), "Introdução: africanidade que luta" in O que é Filosofia Africana?, Cadernos de Ciências Sociais. Lisboa: Escolar Editora.

SIMONE, AbdouMaliq (2004), For the City Yet to Come. Changing African Life in Four Cities. Durham and London: Duke University Press.

SONI, Ambika (2008), An integrated approach is required for a successful 
movement of heritage preservation and promotion. Comunicação feita na Asian Regional Cooperation Conference, representando o Ministério do Turismo e Cultura da Índia. Consultado a 02.12.2008, em http://www.ifacca.org/national_agency_news/2008/12/02/integratedapproach-required-successful-movement-h/

VELOSO, António Matos et al. (2008), João José Tinoco - Arquitecturas em África. Lisboa: Livros Horizonte.

VICENTE, Joaquim et al. (2002), Antigo Bairro Militar de Maputo. Maputo: Edições FAPF, Universidade Eduardo Mondlane. 